University of Wollongong

Research Online

Faculty of Law, Humanities and the Arts Papers (Archive)

$1-1-2012$

Poor mothers and lonely single males: the 'essentially' excluded women and men of Australia

Roger Patulny

University of Wollongong, rpatulny@uow.edu.au

Melissa Wong

University of New South Wales

Follow this and additional works at: https://ro.uow.edu.au/lhapapers

Part of the Arts and Humanities Commons, and the Law Commons

Research Online is the open access institutional repository for the University of Wollongong. For further information contact the UOW Library: research-pubs@uow.edu.au 


\title{
Poor mothers and lonely single males: the 'essentially' excluded women and men of Australia
}

\begin{abstract}
It is unclear how much gendered social exclusion and disconnection reflects a problem or a preference. Women may prefer market-disengagement despite the risk of exclusion from 'normal' social activities through financial incapacity, and men may prefer marketengagement despite the risk of disconnection from informal social networks. This article examines these issues amongst Australian men and women. It finds women, particularly single and low-income mothers, are more socially excluded, and men, particularly single middle-aged men, are the most socially disconnected, after preferences. Future policy should be cognisant of contact preferences, intra-household support dynamics, long work hours and prevailing gender norms.
\end{abstract}

\section{Keywords}

men, australia, males, excluded, single, lonely, women, mothers, poor, ERA2015

Disciplines

Arts and Humanities | Law

\section{Publication Details}

Patulny, R. \& Wong, M. (2012). Poor mothers and lonely single males: the 'essentially' excluded women and men of Australia. Social Policy and Society, 12 (2), 221-239. 


\title{
Poor Mothers and Lonely Single Males: The 'Essentially' Excluded Women and Men of Australia
}

\author{
Roger Patulny* and Melissa Wong** \\ *School of Social Sciences, Media and Communication, University of Wollongong \\ E-mail: rpatulny@uow.edu.au \\ ** Social Policy Research Centre, University of New South Wales \\ E-mail: melissa.wong@unsw.edu.au
}

It is unclear how much gendered social exclusion and disconnection reflects a problem or a preference. Women may prefer market-disengagement despite the risk of exclusion from 'normal' social activities through financial incapacity, and men may prefer marketengagement despite the risk of disconnection from informal social networks. This article examines these issues amongst Australian men and women. It finds women, particularly single and low-income mothers, are more socially excluded, and men, particularly single middle-aged men, are the most socially disconnected, after preferences. Future policy should be cognisant of contact preferences, intra-household support dynamics, long work hours and prevailing gender norms.

Keywords: Social exclusion, social disconnection, gender, necessity, income, marital status, ageing.

\section{Introduction}

An important omission in studies of 'social' phenomena, particularly social exclusion and social connection, is the degree to which people feel they need to be socially engaged. A lack of social engagement is usually assumed to be a 'bad thing'. However, this assumption can be criticised for ignoring whether actual social engagement reflects what is deemed to be essential by the people themselves.

Essentialness is important to the study of social exclusion, and derives from early UK studies by Mack and Langsley (1985) which aimed to identify a consensual definition of poverty using a set of items that people regarded as necessary, and which all adults should be able to afford and which they should not have to do without. Empirically, they sought to distinguish between items that people did not want from items they wanted but could not afford as better 'essential' indicators of exclusion from 'normal' social activity. Studies focusing on the essentialness of items including social activities have been conducted in countries including Britain, Ireland, Denmark, Germany, Russia, Tanzania, Vietnam and Yemen (Gordon, 2006: 44-5), and recently in Australia (Saunders et al., 2007). Ignoring the essentialness of an item runs the risk of inappropriate or insufficient policy responses to social exclusion. These issues are exemplified particularly well in the context of gendered social exclusion and connection in Australia.

Social exclusion is often predicated on economic capacity to participate socially (Levitas et al., 2007), which is likely to disadvantage females, given their reduced financial 
capacity through lower wages and retirement benefits (income, age) and greater income and time poverty through single parenthood (marital status). However, females might find reduced income preferable to working longer hours, which would limit the capacity for 'essential' social time and maintaining friendship networks, and it is unclear that this is accounted for in existing policy. Evidence of greater social exclusion amongst women such as single mothers in Australia (Saunders et al., 2007) has been met by a policy response to push women into employed work at earlier stages of their children's lives through welfare payment disincentives (Grahame and Marston, 2011). This has occurred in spite of feminist researchers noting the 'essentialness' of non-market familial and community relations (Jackson, 1999), autonomy, independence and social connection (Millar, 2003) that formal paid work commitments can erode.

Conversely, social capital is often predicated on maintaining informal social networks, which may disadvantage men through working excessive hours as primary householdproviders (income, marital status) and an easier deterioration of networks following retirement (age) and marital separation. However, males might simply prefer or not need social support to the same degree as females. Evidence of social disconnection amongst older men in Australia (Findlay and Cartwright, 2002; Patulny, 2009) has accompanied policy initiatives aimed at improving connections amongst older, such as men's sheds and self-activation programs (Cattan et al., 2005). However, there has been little recognition and few policies aimed at addressing social disconnection amongst other types of men, an inertia likely driven by the popular perception that men simply don't find social activity as 'essential' as women.

These examples show the importance of understanding 'essential' social exclusion and disconnection in developing research and policy, and no study to date has compared incidence, preferences and policy implications of social capital and exclusion along gendered lines. This article will examine these qualities for Australian men and women, using the 2006 Community Understanding of Poverty and Social Exclusion (CUPSE) survey. It acknowledges that gender is a complex notion, with varying definitions according to different theories of feminism and sexuality (Connell, 2009). However, it builds on a growing tradition of empirical, quantitative research on gender in Australia (Craig and Mullan, 2009; De Vaus et al., 2009; Baxter and Hewitt, 2011) that focuses on the differences and inequities between men and women as common empirical categories in Australian society. It builds on intersectionality ideas suggesting that gender is not a uniform identity category, but one that intersects with the politics of difference and various categories of disentangle such as race or class (Yuval-Davis, 2006). In keeping with this, the study will not only look at gender as a single predictor in running regression models, but in interaction with other key demographic qualities, including income, household qualities such as marital status, and social network and mobility aspects associated with ageing. This study will include these variables and interactions, and differentiate between social disengagement as a general outcome and as an outcome perceived as 'essential'.

\section{Gender differences in disconnection and exclusion}

Social exclusion, social connection and gender

There is no clearly accepted definition of social exclusion, although consensus is emerging on key elements, such as its being a relational concept with multiple dimensions linking 
economic, social, political and cultural factors (Millar, 2007; Hulse et al., 2011). From earlier UK government definitions about the negative consequences of linked problems such as unemployment, poor housing and high crime, for example (Department of Social Security, 1999), it has become a term denoting active social engagement within Australian policy discourse (Hayes et al., 2008; Australian Social Inclusion Board, 2009). Most attempts to measure social exclusion (Burchardt et al., 1999; Hills et al., 2002; Bradshaw et al., 2000; Levitas et al., 2007; Saunders et al., 2007; Boon and Farnsworth, 2011) emphasise the economic incapacity behind social exclusion, and many feminist researchers highlight this as well. Economic aspects of social exclusion can be seen in relation to gendered understandings of 'marginality' from the market (Jackson, 1999), the absence of gender-neutrality in social and economic institutions (Rees, 1998), and the structures and systems that enforce gender inequality (Levitas et al., 2007). However, the social participation dimensions themselves are less well recognised and researched, and few empirical studies explicitly test gendered social participation using the rhetoric of social exclusion.

The concept of social capital is likewise contested, but most commonly emphasises social engagement (Putnam, 2000) with a focus on social networks as the key antecedent (Bourdieu, 1986; Coleman, 1990). International studies produce mixed results about gender (Ogg, 2005; Gray, 2009), but several studies have found that Australian men have poorer social support networks and higher levels of loneliness (Flood, 2005; Heady and Warren, 2007; Franklin and Tranter, 2008). The social capital distinction between localised informal 'bonding' and broader formal 'bridging' networks (Putnam, 2000; Patulny and Svendsen, 2007) also has likely gender dimensions. Van Emmerick (2006) suggests that males are more interested in 'hard', specialised, formal workoriented connections that enhance careers, while women prefer 'softer' more familiar, informal emotional relations. However, most empirical studies of gendered social capital focus on how it improves ends, such as workplace advancement (Timberlake, 2005) or educational/career success (Parks-Yancy et al., 2006), rather than on the actual engagement or bonding/bridging 'trade-offs' of men and women.

The idea of gender trade-offs centralises the issue of social participation preferences, although there is scant literature on the subject. The emphasis on labour market engagement within most social exclusion rhetoric downplays the value of non-market labour and social organisation, and the significant preferences of many women not to be more 'included' in an individualised capitalist labour market (Jackson, 1999). Fleming (1999) too suggests that men may be 'shackled' by their work-oriented gender roles, and may prefer to have better-developed social and family networks. On the other hand, Joiner et al. (2002) draw a distinction between 'social' (lack of pleasurable engagement) and emotional (incidence of powerful disconnection) loneliness, and theorise a preference for the former to avoid the latter. In the only study to explicitly test necessity, Saunders et al. (2007) found support for the 'essentialness' of social connection measures, but did not look explicitly at gender distinctions.

The task, then, of understanding gendered social exclusion and connection should focus on preferences as much as incidence. It should also be cognisant of the influence of other key demographic qualities that might interact with gender. We briefly discuss the three key socio-economic indicators that are likely to interact strongly with gender in predicting social disconnection and exclusion: income, marital status and age.

Income, also serving as a proxy for labour market participation, is the most obvious covariate for social exclusion, and is important for social disconnection as well. A gender 
wage gap remains in the US and many other countries (England, 2005), and lower levels of social contact are recorded amongst those who are on low income or unemployed in a number of studies (Hughes and Black, 2002; Stone et al., 2003; Lindsay, 2009). Gray (2009) notes that there is 'declining solidarity' of care and increasing residential elder care, which she (2009) suggests may be due to 'daughters having less time' with rising female employment.

Gender researchers point to the primacy of partnership and parenthood in shaping gender inequities. It has long been noted that female partners often provide social support and networks for their male counterparts (Lowenthal and Haven, 1968; Gerstel et al., 1985). Marital breakdown is also linked to social and economic distress and the loss of joint networks (Shapiro and Keyes, 2008; De Vaus et al., 2009), while separated men and fathers exhibit very high levels of isolation and loneliness (Flood, 2005; Franklin and Tranter, 2008). Familial connections are not without their own social penalty, however, with Robinson and Godbey (1997) finding reduced social contact amongst American married parents, and Osborne et al. (2008) finding that women often have difficulty combining community group involvement with family responsibilities.

Age is also extremely relevant, as gender dynamics change across the life-course (Cherry, 2007). Those with marginal workforce attachment and/or low earnings, females, accumulate relatively low levels of retirement income, or else have no coverage at all (Pinquart and Sörensen, 2001; Rosenman and Scott, 2009). Those with marginal social attachments experience greater isolation, including those ageing alone (Warburton and Cordingley, 2004), retired men (Patulny, 2009), but also middle-aged men and women (Hawthorne, 2008). There is also a related literature on young men and social inclusion in settings of male violence and repressive norms of masculine behaviour (Barker, 2005).

\section{Policy implications of gendered social connection and exclusion}

Gender is implicit in most policy strategies aimed at fostering social inclusion and connection, although usually with an economic focus. Policies aimed at redressing social exclusion are macro-welfare policies, and several critiques have emphasised the need to expose the lack of gender neutrality in social institutions (Rees, 1998; Jackson, 1999; Levitas, et al., 2007). More specific policies include mandating equal pay structures for women (which has not occurred in twenty-six middle- to high-income countries), transferring public income to alleviate gender poverty linked to child-care, supporting marital-partnership relations that provide crucial income support for women, supporting single mothers, social job-training funds, tax credits and work-life balance initiatives (Gornick and Janti, 2010; Scott, 2008). However, most such macro-policy is oriented to the alleviation of poverty rather than actual social engagement with other people.

Many policies aimed at redressing social isolation are focussed on older people. Findlay and Cartwright (2002) noted that early intervention support groups and structured group interventions have had some success in reducing social isolation amongst older people. They suggest strategies such as linking young families and isolated older persons, setting up community-based common projects, 'gate-keeper' projects to identify at-risk older people and old-young home-share programs. Similarly, in a review of interventions evaluated using control-group methods, Cattan et al. (2005) found that programs such as 
education, counselling, self-help and hobby (self-activation) groups in community centres produced significant improvements in social contact.

However, such strategies will lack effect if they ignore social contexts and preferences. Franklin and Tranter (2008) point to a 'masculine' resistance to using phone and email contact to combat loneliness, and a general reluctance to engage with 'standardised' services, noting that 'just putting old people together in day centres is not an answer to their loneliness, as one old woman told me very clearly' (ibid.: 18). Collery (2002) criticises the bias towards 'feminine' self-sacrifice amongst mentors and labour market engagement amongst disaffected youth in 'engagement mentoring' policies. This again highlights that preferences are key to understanding social exclusion and connection, and improve policy responses.

\section{Data and formatting}

Data source

The data used in this article are from the Community Understanding of Poverty and Social Exclusion (CUPSE) survey conducted in 2006 (Saunders et al., 2007). This was the first survey conducted in Australia in which respondents were asked whether they thought that a range of items was essential in that 'no one in Australia should have to go without', ${ }^{1}$ whether or not they had the item and, if they did not have it, whether or not this was because they could not afford it. Weights were constructed to correct for sample overrepresentation of older, educated and coupled households. Table 1 describes the final, weighted, sample, broken down by gender, marital status, income and age.

Table 1 CUPSE sample composition by socioeconomic characteristics (percentages, weighted)

\begin{tabular}{llrr}
\hline \hline & & per cent & \multicolumn{1}{l}{$\mathrm{N}$} \\
\hline Gender & Male & 48.5 & 1,054 \\
Marital status & Female & 51.5 & 1,119 \\
& Single & 21.0 & 457 \\
& Married no child & 39.0 & 848 \\
& Married with child & 20.8 & 453 \\
& Separated no child & 14.1 & 306 \\
Income (equivalised, & Separated with child & 5.1 & 110 \\
disposable) & Low - bottom 30\% & 21.9 & 553 \\
& & & \\
Age categories & Medium - middle 50\% & 51.7 & 1,084 \\
& High - high 20\% & 26.4 & 460 \\
Total sample size & 18-34 & 27.2 & 591 \\
\hline \hline
\end{tabular}

Notes: Percentages are expressed after omitting missing values. 


\section{Social disconnection and exclusion variables}

Our variables were defined and selected on the basis of lacking contact or support as the indicators for social disconnection (SD), or the ability to participate in 'normal' social activities as the indicator for social exclusion (SE). Social exclusion is defined here in a more restricted sense than used in previous studies (Saunders et al., 2007), emphasising social disengagement rather than deprivation or exclusion from services. Six variables were selected in all:

- regular social contact with other people (SD)

- to be treated with respect by other people (SD)

- someone to look after you if you are sick and need help around the house (SD)

- a special meal once a week (SE)

- a night out once a fortnight (SE)

- a week's holiday away from home each year (SE)

These questions were selected on the basis of being largely 'social' in character, asking respondents both whether they lacked the item and whether they believed it was essential for most people to have, being applicable to the whole population (thus we excluded presents for family, family support and activities for children) and not repeating each other (thus we excluded acceptance by others when results were largely identical to being respected by others).

Interpretation of results is slightly harder than in other studies. Lacking the item absolutely but not essentially may sometimes mean the respondent feels that they (or others) do not deserve the item, as may be the case with respect from others, but generally it suggests that the loss is not as severe as might have previously been suspected. Lacking the item essentially but not absolutely represents what would be a usually 'hidden' case of exclusion, whereby amongst a group of people who do not on average lack an item, there exists a small sub-group of people who do, and care about it. The lack is not as severe as lacking in both an absolute and essential sense, in that it affects fewer people (even if the severity is great). Those who both lack in an absolute and essential sense are the most socially disconnected and excluded of all persons.

\section{Independent variables and models}

Following a brief overview of some basic descriptive statistics, we present results from several regression models interacting gender with each of the key variables: marital status (single, married with/without children, separated with/without children), income (high, medium, low) and age (young, middle age, old). Dummies were created for each category and interaction. Income was preferred over employment status as the primary indicator of socio-economic status. We avoided interactions between employment status and gender in conjunction with other interactions because of resulting small cell sizes and joint co-linearity between employment, income and ageing (retirement).

Other controls were fairly typical of most social disconnection and exclusion studies, including employment status, education, disability and ethnicity (Hughes and Black, 2002; Stone et al., 2003; Putnam, 2000; Heady and Warren, 2007; Saunders et al., 2007). We also included controls for mental health, or, more precisely, the presence of depression, loneliness or anxiety, given research connecting social support obligations 
to stress amongst women (Kawachi and Berkman, 2001) and social disconnection to depression and loneliness for men (Miller et al., 2005). The reference category was selected to represent a middle-class/middle-aged person, born in Australia and in reasonable physical and mental health.

Linear probability models were employed, producing estimates of the marginal probability (change in predicted probability) of lacking the relevant indicator based on a one-unit change in the independent variable. Four models were run for each social connection indicator, using gender interactions and other demographic controls, predicting (1) the likelihood that the person lacks the item in an absolute sense (Don't have), (2) the likelihood that the person lacks the item in an essential sense (Don't have + essential) and (3) and (4) repeating these models controlling for mental health. The models for the social exclusion indicators were identical to social disconnection, but have the added benefit of including a control for the affordability of the item along with mental health controls $(\mathrm{MH}+$ afford). Significant effects are presented below for each of the key independent variables interacted with gender: income, marital status and age.

\section{Results}

Figure 1 below shows a descriptive overview of social disconnection and exclusion faced in Australia. Percentages of persons who lack the item and deem it to be essential are nested within the total percentages of persons lacking the item, and, in the case of social exclusion, affordability is further nested amongst these categories. Social exclusion (as defined and measured here) is much more widespread than social disconnection, and aggregate gender differences are not large. There is nonetheless broad confirmation that males generally lack social connection and females lack social inclusion.

Males are more likely to lack social contact and support when sick, though differences are lessened when assessed on the basis of whether the item is essential or not. Females

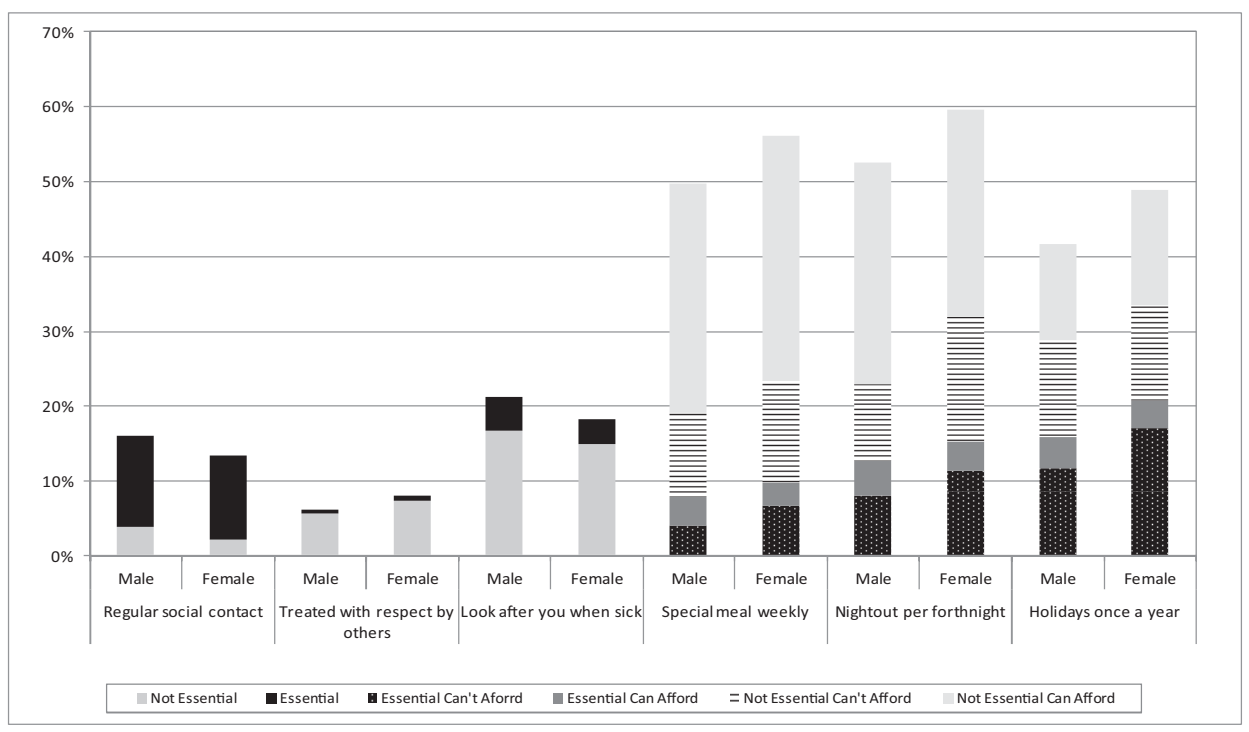

Figure 1. Social disconnection and exclusion, overview. 
are more likely to lack respect. They are also more likely to lack a week's holiday away from home, a night out and a holiday once a year, whether by absolute or essential measures. The greater part of the difference is explained by affordability rather than gender differences in perceptions of essentialness.

\section{Regression-based marginal effects - high income}

We look at the gender-income interactions in the first instance, as the primary socioeconomic contributor to social exclusion, and as a proxy for employment status. Highincome females do extremely well in avoiding social disconnection and exclusion. They are less likely to lack someone to look after them or a night out in general, and less likely to feel they are not treated with respect and to lack a special meal and to have a holiday, both in general and in an essential sense. High-income males, however, are 7 per cent more likely to lack a holiday in general and 15-18 per cent more likely to lack an essential weekly meal, all of which they can afford. This is likely to be explained by time pressure, in that high-income males in Australia have experienced a large increase in work hours and subsequent time pressure (Craig and Mullan, 2009).

Keeping in mind that these findings are not from matched household data, it nonetheless suggests an intra-household transfer of resources is taking place within high-income households (much as in married childless households, above). That is, high-income males subsidise the social activities of high-income female at least to some degree, which results in them being one of the least excluded groups out of all those examined in this article and high-income males are not.

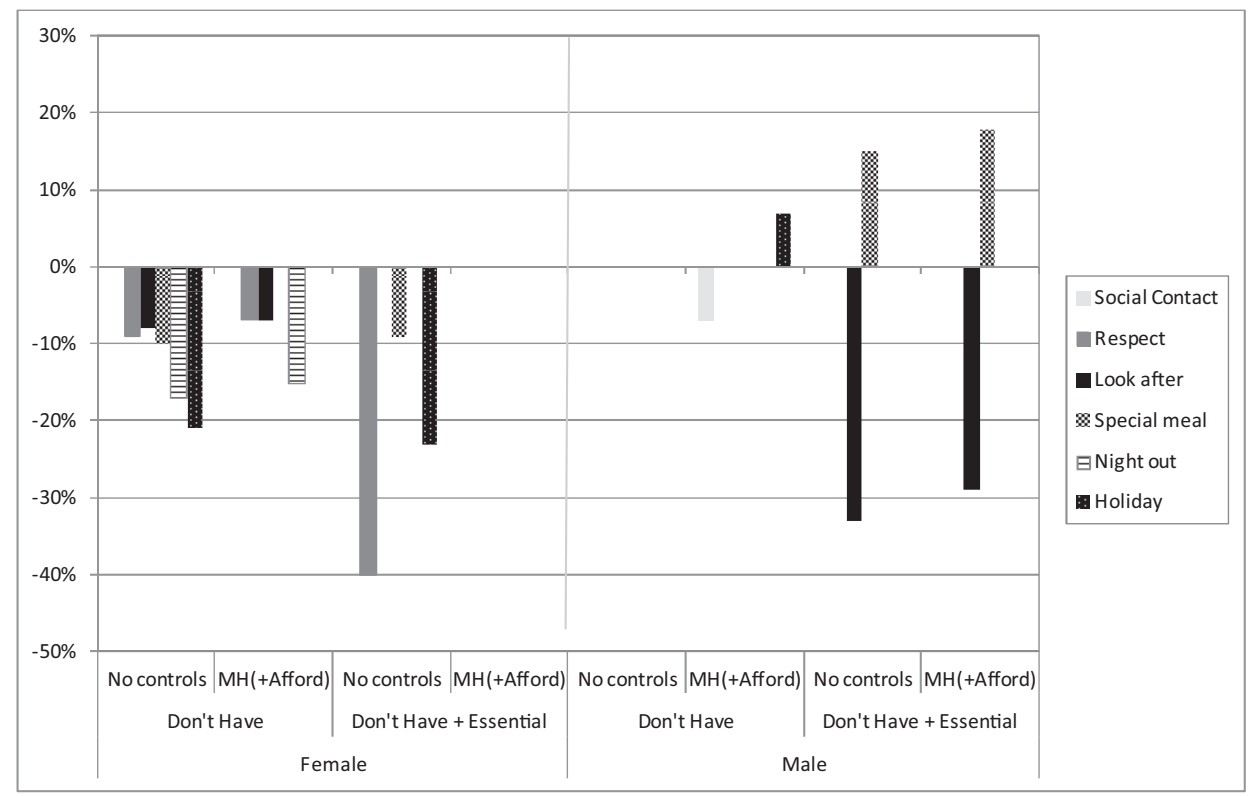

Figure 2. Social disconnection and exclusion, high-income persons. 


\section{Low income}

Just as richer females do well in avoiding social disconnection and exclusion; it seems that poorer females do worse. Low-income females are 10 per cent more likely to lack social contact regardless of controls, 7 per cent more likely to lack someone to look after them before mental health controls and 10 per cent more likely to lack a night out after affordability controls. They are also 11-14 per cent more likely to lack a holiday and an essential holiday, the latter regardless of controls. Low-income males on the other hand are less likely to lack social contact (15-16 per cent) and someone to look after them (23 per cent) in general and holidays (29 per cent) when regarded as essential, regardless of controls.

These findings are the mirror image of the high-income case, and are indicative of likely intra-household transfers of resources this time from females to males. In particular, low-income males rarely lack someone to look after them in general or an essential holiday, while similar females lack both; and neither result is explained by affordability. The most likely explanation for this is a disparity in free-time arising from such females assuming the greater burden of care, which would explain why low-income females are one of the most excluded groups out of all those examined (often regardless of affordability), and low-income males are not.

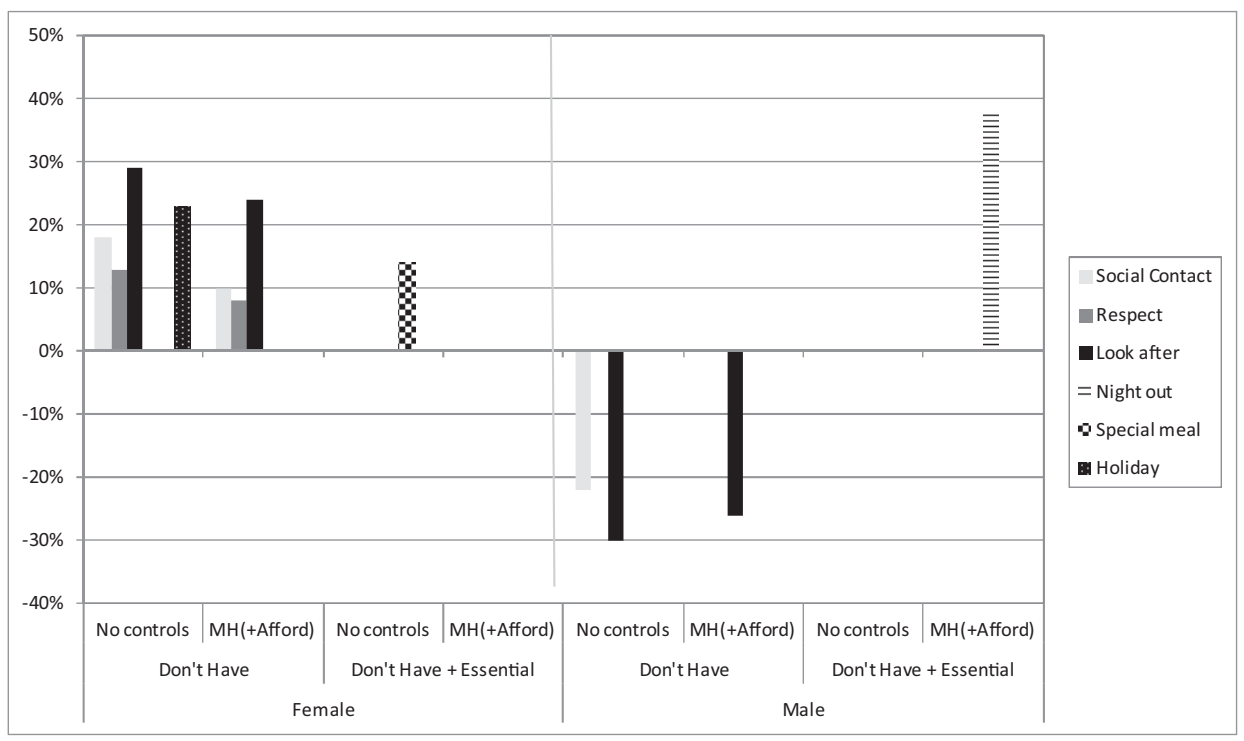

Figure 3. Social disconnection and exclusion, low-income persons.

\section{Married/de-facto with children}

Married/de-facto fathers show few differences from married mothers (reference category) in social disconnection and exclusion. Married/de-facto fathers with good mental health (who do not feel isolated) are 8 per cent more likely to lack social contact and 7 per cent less likely to lack a holiday (explained by affordability), and there are no 'essential' differences between married fathers and mothers according to any indicator. 


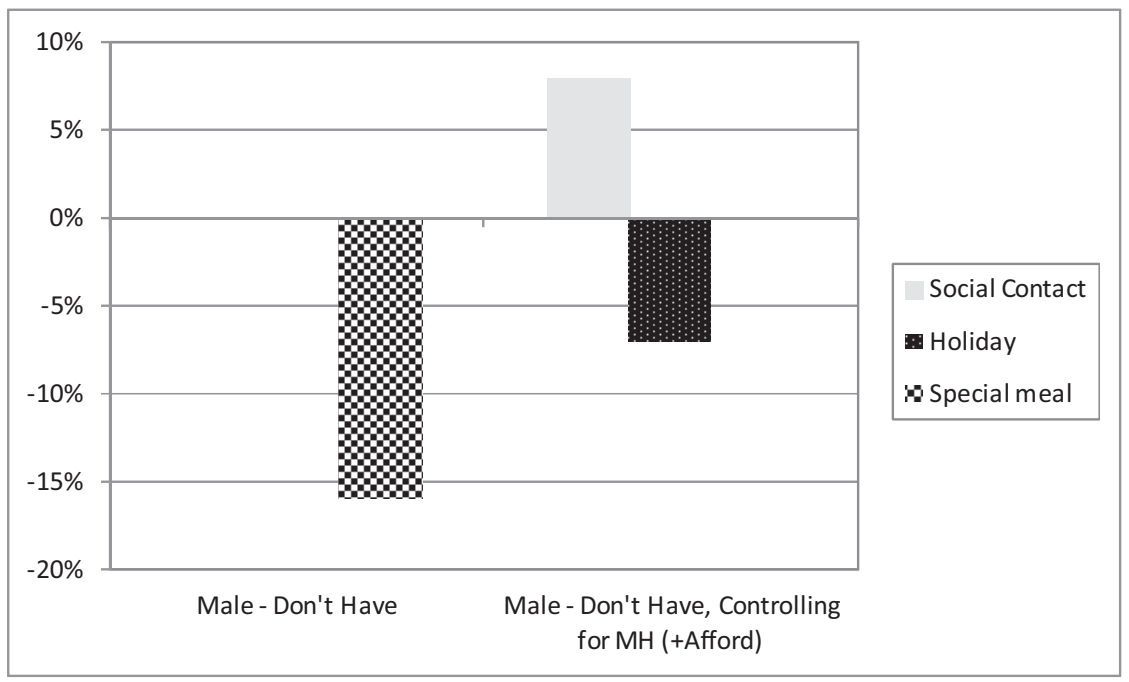

Figure 4. Social disconnection and exclusion, married/de-facto persons with children.

\section{Married/de-facto no children}

Gender differences in social exclusion start to appear when looking at married/de-facto persons without children. Childless married/de-facto females are less likely to lack a special weekly meal and night out in an absolute sense, but are 12 per cent more likely to lack an essential night out after controlling for affordability, and are 15-17 per cent more likely to lack an essential holiday. Childless married/de-facto males, on the other hand, are 32 per cent less likely to lack an essential holiday, regardless of controls.

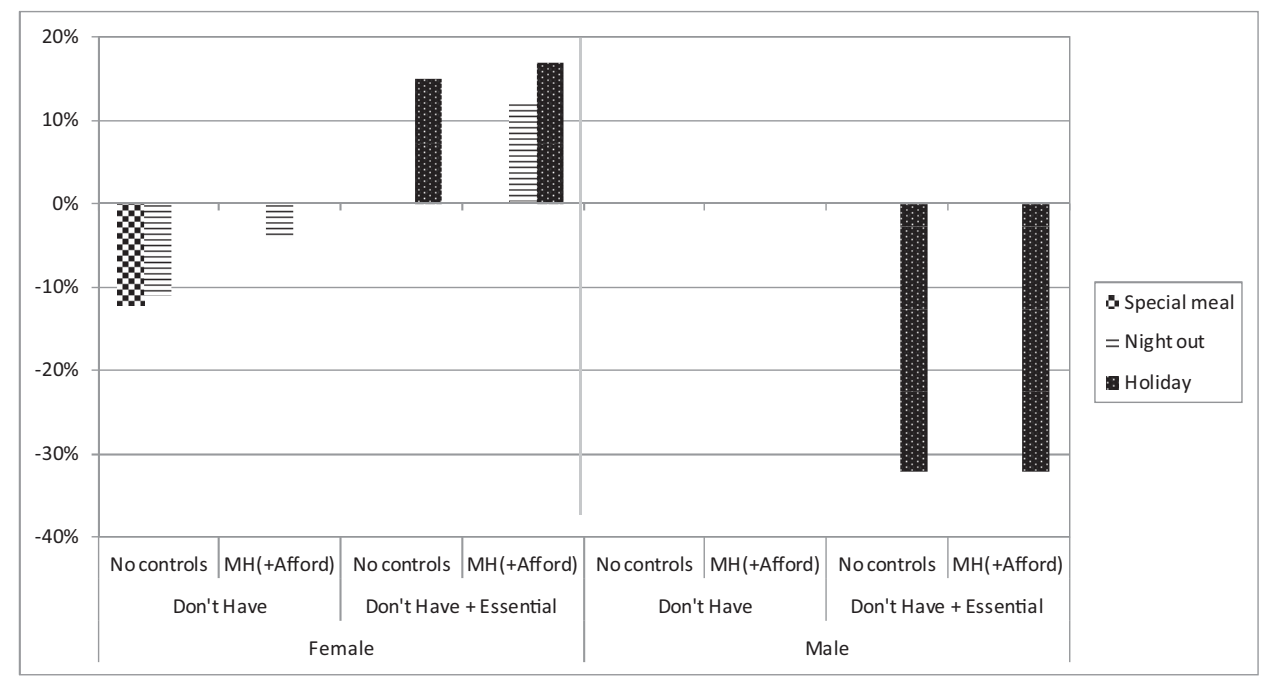

Figure 5. Social disconnection and exclusion, married/de-facto persons, no children. 
Such findings might reflect a social norm of domesticated 'cocooning' or 'nestbuilding' amongst childless and pre-child couples, but this is confounded by male partners being less likely to lack essential holidays. An alternative interpretation, in line with the finding that such females who can afford it do not have nights out, is that females in many childless households are more likely to combine long, full time work hours with a greater share of domestic work than their male partners. This explains the preclusion of essential holidays and nights out for female partners (time pressure) and the taking of essential holidays by male partners (free time), but cannot be tested due to an absence of data on work hours. Regardless, married/de-facto females without children are more socially excluded in that a minority who regard holidays and nights out as essential are unable to take them.

\section{Single, no children}

There are stark differences between single males and females without children. After controls, single childless females show no lack in any indicator, and regardless of controls, they are less likely to lack essential social contact (38-42 per cent), nights out (13-18 per cent) and holidays (15-16 per cent). Single childless males, on the other hand, are more likely to lack social contact (13-17 per cent) and essential social contact (36-45 per cent), regardless of controls. They are 11-12 per cent more likely to feel they are not treated with respect, and to lack someone to support them (23-25 per cent), regardless of controls. And single childless males are 16 per cent more likely to lack a night out until controlling for affordability, and 23-25 per cent more likely to lack an essential night out, regardless of controls.

These results clearly suggest that while single females are good at maintaining social networks, particularly when regarded as essential, single males exhibit extremely

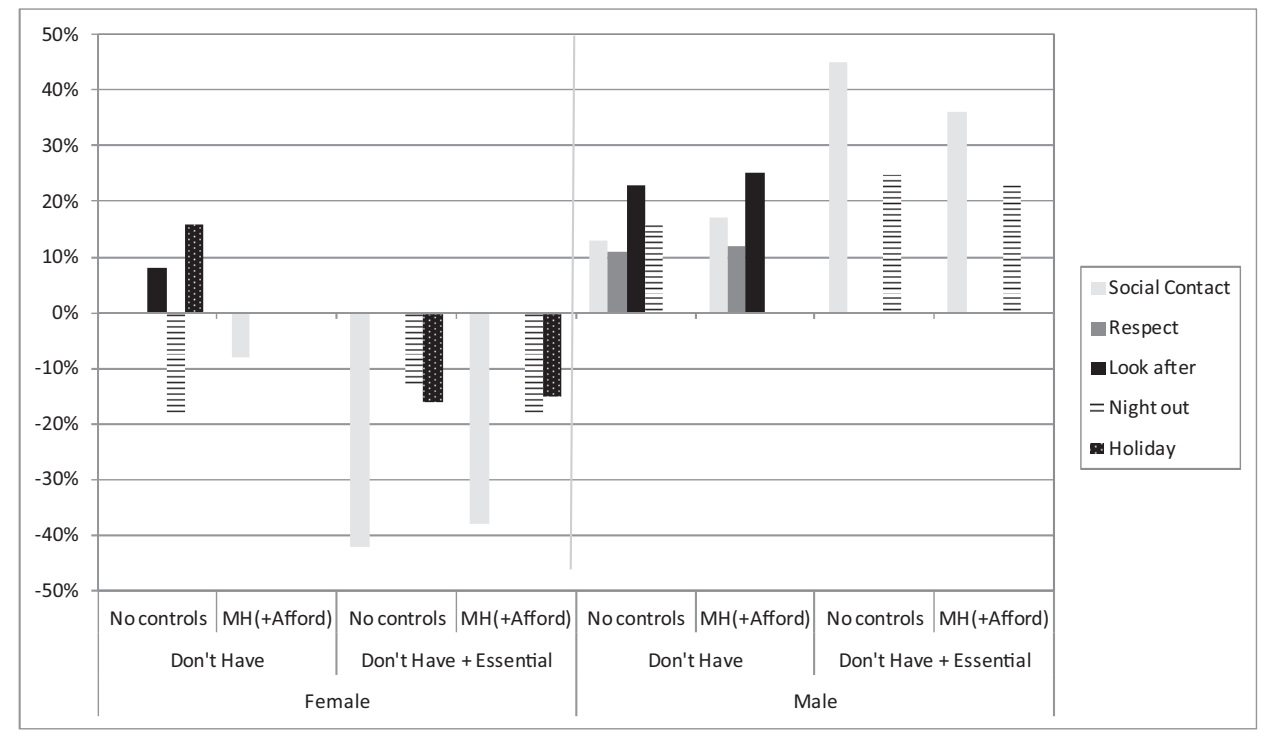

Figure 6. Social disconnection and exclusion, single persons, no children. 
inadequate social networks, and lack contact, support when sick and nights out (despite being able to afford them) as a consequence. They also feel disrespected, which cannot be dismissed on the basis of there being no 'essential' differences in respect, in that single childless males are less likely to think that respect is essential for everyone in general. ${ }^{2}$ This suggests a 'non-virtuous circle' whereby single males return the disrespect they feel from others. On the whole, the pattern clearly shows that single males are not only more likely - and single females less likely - to be systematically disconnected and excluded across a range of indicators, but also that single males are one of the most disconnected and socially excluded of all the groups examined.

\section{Separated with child (lone parent)}

Differences between separated mothers and fathers are surprisingly less severe than for single males and females. Lone mothers appear to be socially disconnected and excluded in general, being 10-18 per cent more likely to lack social contact, 8-13 per cent more likely to feel that they are not treated with respect and 24-29 per cent more likely to lack someone to look after them, regardless of controls. They are also 23 per cent more likely to lack a holiday, which is explained by affordability. However, lone mothers are significantly no more likely to lack any of these things when they consider them essential for most people to have. The only essential item they are more likely to lack is a weekly special meal (14 per cent), which is non-significant when controlling for affordability. Similarly, while lone fathers appear to be less socially disconnected in general, 22 per cent less likely to lack social contact until controlling for mental health and 26-30 per cent less likely to lack someone to look after them, regardless of controls, the only essential lack is a night out, after controlling for affordability and mental health (38 per cent).

This says that, while lacking in a general sense, lone parents may not be as disconnected and excluded as previously thought, in that they do not find many of

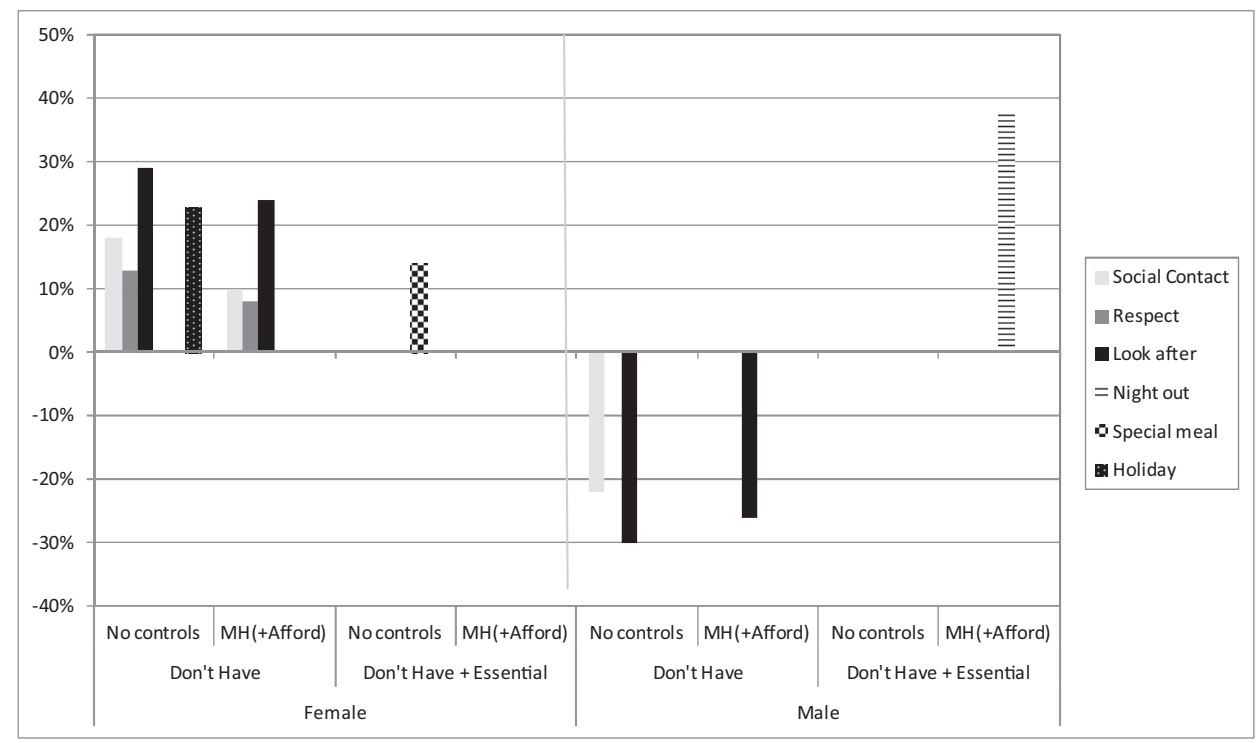

Figure 7. Social disconnection and exclusion, separated persons with children (lone parents). 
these items to be essential to their lives. Lone mothers certainly do worse than lone fathers in a general sense, a likely reflection of the negative impact of time and income poverty for many lone mothers, versus the positive impact of improved social networks for lone fathers resulting from regular (if minor) contact with children. Lone mothers also do slightly worse in an essential sense, given that the perceived lack of respect amongst lone mothers in general (as for single men) may well translate to poor self-image. However, minus the absence of essential meals and nights out, single parents seem able to obtain an adequate level of essential social engagement. Whilst these findings are interesting in themselves, exact interpretation is rendered difficult by the lack of information on how long respondents had been separated for, with a recent study by Baxter and Hewitt (2011) showing a significant recovery in the loss in wellbeing associated with relationship breakdown within a year of the event. Given the strong links between wellbeing and social support noted by these authors, it is plausible that the findings noted in this study may alter with duration of separation.

\section{Separated, no child}

There are large general versus essential differences for separated childless males in particular, such that they are more disconnected and excluded than similar females in general, but not according to essential measures. Separated childless females are more excluded than disconnected, in that they are 14-16 per cent more likely to lack someone to look after them when sick in a general but not essential sense, whilst they are 11 per cent more likely to lack an essential weekly meal and 12 per cent more likely to lack an essential night out. Separated childless males are much more disconnected and excluded

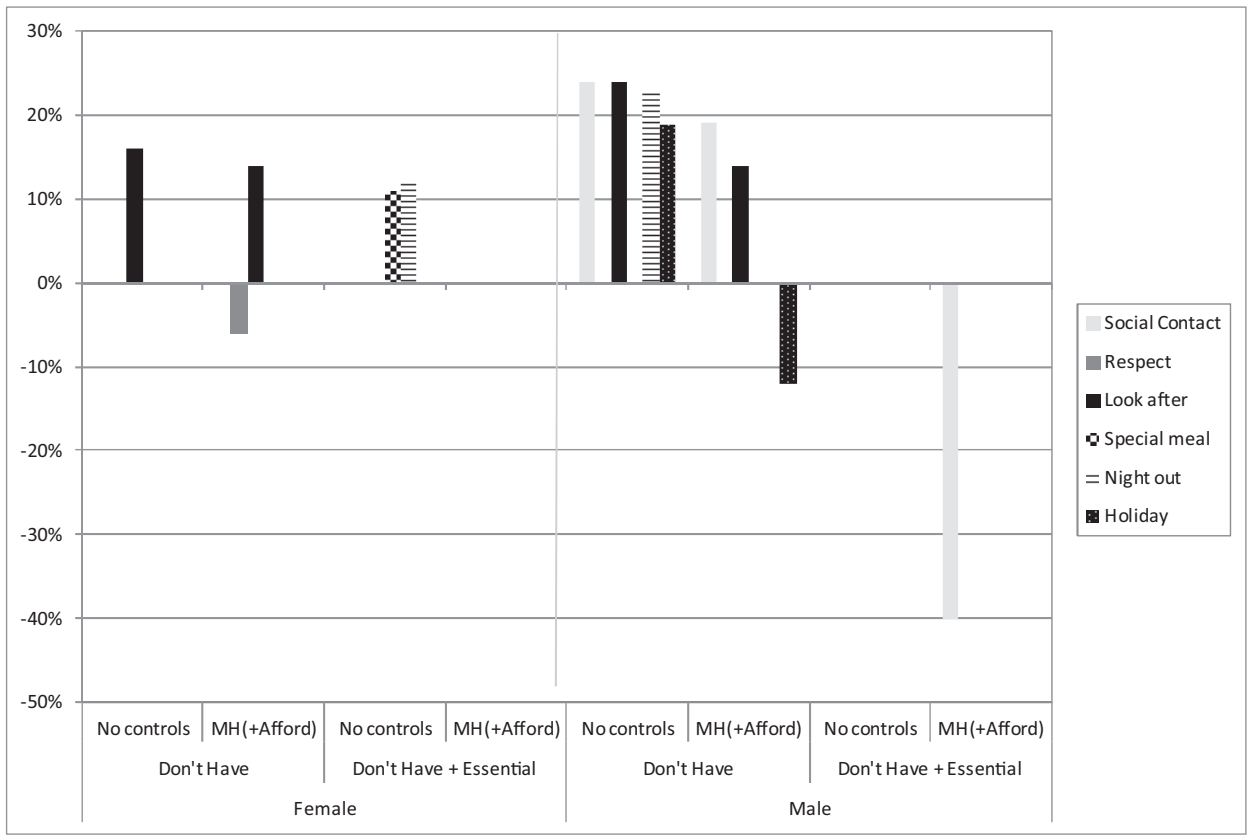

Figure 8. Social disconnection and exclusion, separated persons, no children. 
in general; they are 19-24 per cent more likely to lack regular social contact, 14-24 per cent more likely to lack someone to look after them, 23 per cent more likely to lack a night out, and 19 per cent more likely to lack a holiday. However, none of these is significant in predicting an essential lack of any kind, and in fact separated childless males are 40 per cent less likely to lack essential social contact after controlling for mental health (depression).

This suggests that while separated childless males are more disconnected and similarly excluded in comparison to separated childless females in general, separated childless females are more excluded in that they care about their lost meals and nights out to a much greater extent.

\section{Younger persons}

The effects of youth are mixed, with young females 6 per cent more likely to lack social contact and respects in general, explained by mental health controls. They also go from a lower likelihood of lacking a special meal and night out in general to a higher likelihood of lacking an essential special meal (11 per cent; explained by 'depression' mental health controls) and night out (14 per cent; explained by affordability). Young men on the other hand are more likely to lack a special meal in general (14 per cent), explained by affordability, but are less likely to lack nights out and respect in general. They are also less likely to lack essential social contact and someone to look after them after controlling for mental health. Overall, youth is associated with greater social exclusion amongst females than males.

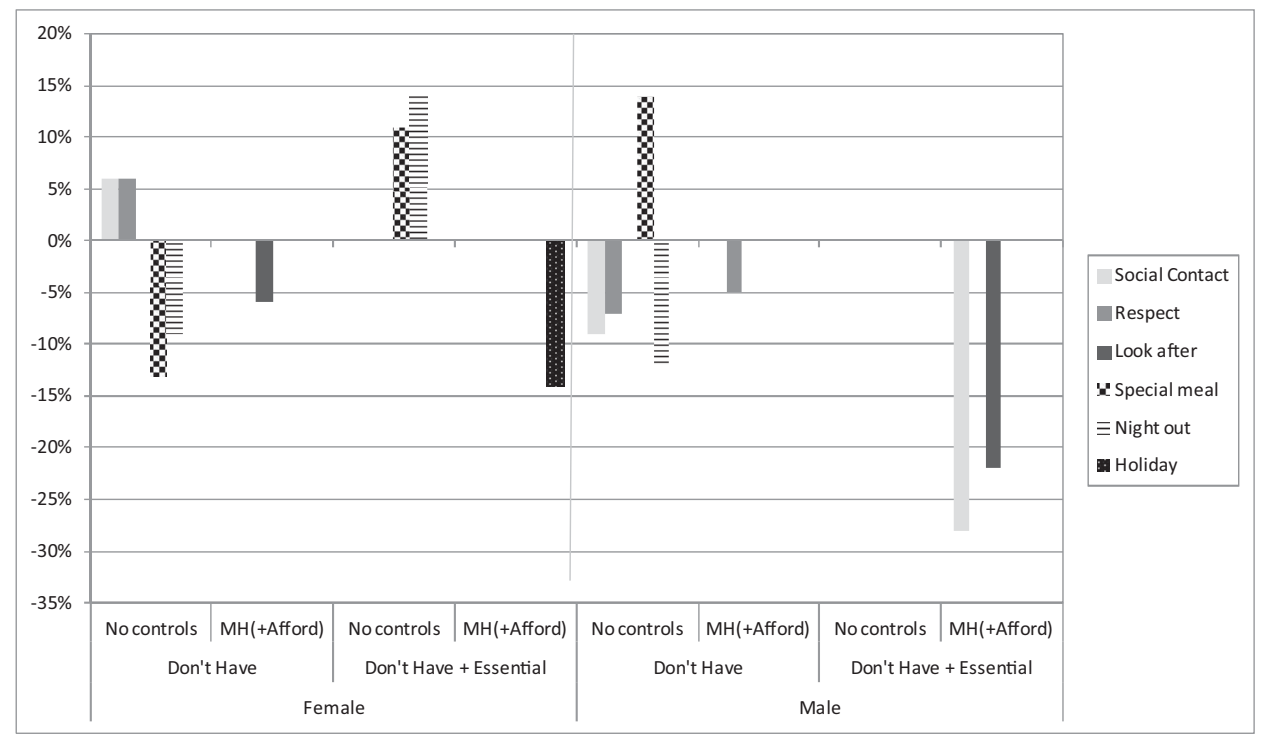

Figure 9. Social disconnection and exclusion, younger persons.

\section{Older persons}

There are surprisingly few significant differences associated with old age. Older females are slightly more likely to lack a holiday generally (7 per cent) after controlling for 
affordability, but are not excluded or disconnected from anything they regards as essential. These findings are surprising given the low incomes of many older women (i.e. pensioners), but may reflect the satisfaction of many older persons with cheaper substitutes at local clubs and societies, for example. Older males, though no less likely to feel treated with respect in general, are far more likely (53-4 per cent) to feel that they are not treated with essential respect regardless of controls, and are 20 per cent more likely to lack an essential holiday, even after controls, a possible reflection on disconnection and having a lack of other people to go on holiday with.

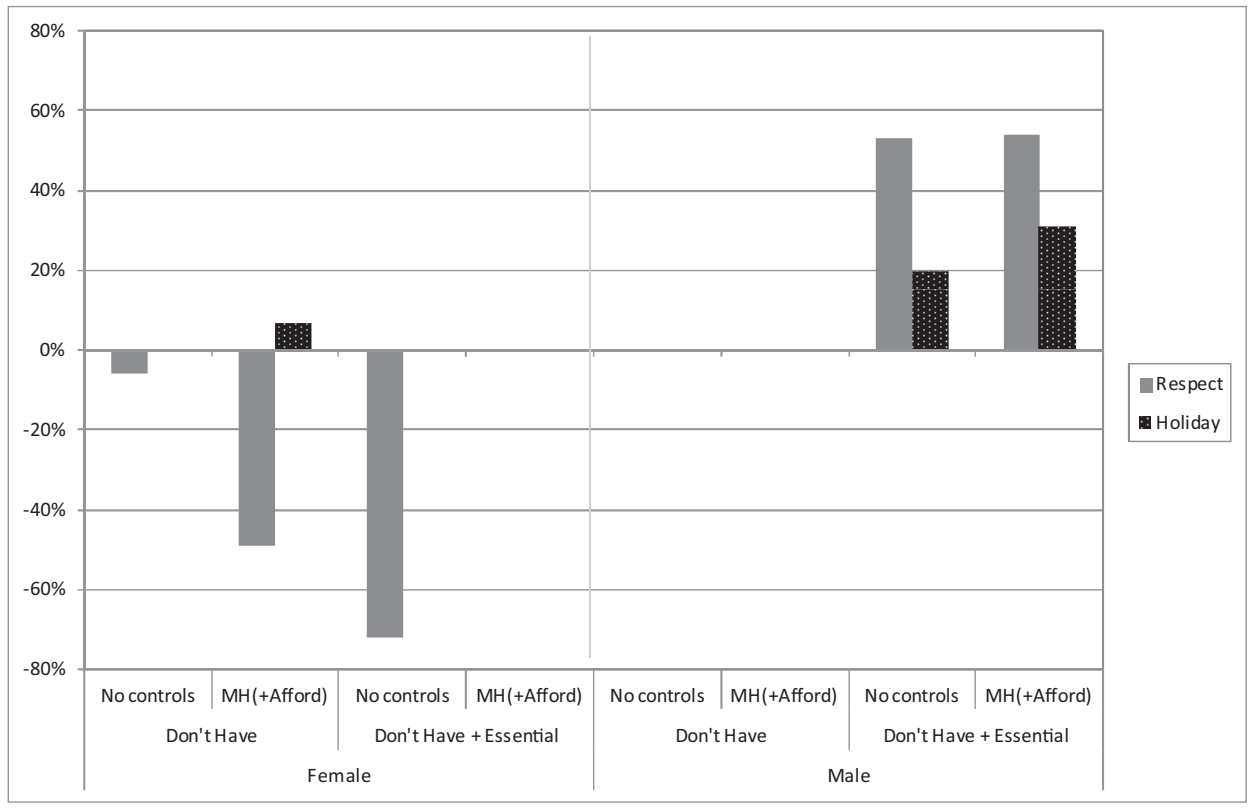

Figure 10. Social disconnection and exclusion, older persons.

\section{Summary and discussion}

This study has found implications for gender along a number of dimensions. There are clear differences across socio-economic categories of males and females, some operating at the expense of others. Single males are probably the most disconnected/excluded of all groups examined, while low-income females also show substantial levels of social exclusion. Both of these results are in stark contrast to their low/high-income partners who are far less likely to be disconnected or excluded, and reflect a likely intra-household transfer of resources confirming suggestions that social exclusion is best understood in terms of resources and dependencies within households (Millar, 2003). There are, overall, more categories of females than males disconnected/excluded, although the two least disconnected/excluded groups are also female (single and high income). Also, affordability and mental health issues have a greater impact upon the disconnection/exclusion of females than of males. 
Taking these factors into consideration, there is support for the theory that males are more disconnected, in terms of lacking social contact and respect in key categories, and females more excluded, in terms of lacking nights out, weekly meals and holidays. One key weakness of this study, however, is the omission of a control for work hours, which was unavailable and may shed more light on the exclusion/disconnection of men in particular.

There are several policy implications. There is a clear need to support macro-policies aimed at helping lone-parent mothers and low-income women in particular, but such policies must be cognisant of gendered preferences for 'essential' social interaction, as well as intra-household support dynamics. Simply pushing more employment-based strategies and requirements on women already in difficult situations (Collery, 2002) will not result in improving 'essential' inclusion, and most probably will undermine the employment seeking goals as a consequence. This is reflected in housing policy research, with Hulse and Saugeres (2008) finding that low-income women and single mothers in public housing resist financial policies to work because of strong personal commitments to parenting and voluntary activity. So too is there a need to provide more social support for men in general, particularly (and surprisingly) middle-aged single men at least as much as older men. Again, this must reflect preferences, rather than the convenience of centralised 'day centres' (Franlkin and Tranter, 2008), and account for the constraints imposed by long work hours and the prevailing norms of masculinity.

Key themes for future research also emerge from this study. Hulse and Saugeres (2008) point to a significant gap in research into single men and women, and the findings in this research concerning single mothers and single men reinforces the need to expand work in this area. Hulse and Saugeres also find that mental health issues form an important barrier to finding work amongst sole parents and single persons; the present findings build on this to suggest that issues of income, mental health and social inclusion are closely inter-connected. Identifying causal effects amongst these issues is another object of future research. Another key issue for future research is how these factors play out in the context of culturally and linguistically diverse persons (CALD). CALD groups are often 'hard to reach' due to language, cross-cultural factors, location/resettlement in rural areas, and often lose contact with pre-existing informal social networks following migration (Torezani, et al., 2008; Fozdar, 2011). They are also often subject to stigma and discrimination (Dunn et al., 2004). The gender dimensions and essentialness of social inclusion for CALD groups is presently unclear.

\section{Acknowledgement}

We would like to acknowledge the support of Peter Saunders in commenting on previous versions of this article and in providing access to the CUPSE data.

\section{Notes}

1 The list of essential items was developed after listening to the views of low-income Australians through a series of focus groups (Saunders and Sutherland, 2006). For more information on this, refer to Saunders et al. (2007: Chapter 4).

2 Calculated from separate regressions not reported here, but available on request. 


\section{References}

Australian Social Inclusion Board (2009) Social Inclusion: A Compendium of Social Inclusion Indicators How Is Australia Faring?, Canberra: Australian Government.

Barker, G. T. (2005) Dying to be Men: Youth, Masculinity and Social Exclusion, New York: Routledge.

Baxter, J. and Hewitt, B. (2011) 'Relationship transitions and subjective wellbeing: a longitudinal analysis', paper prepared for the HILDA Survey 10th Anniversary Research Conference 2011, University of Melbourne, 14-15 July.

Boon, B. and Farnsworth, J. (2011) 'Social exclusion and poverty: translating social resources into accessible resources', Social Policy and Administration, 45, 5, 507-24.

Bourdieu, P. (1986) 'The forms of capital', in J. Richardson (ed.), Theory and Research in the Sociology of Education, New York: Greenwood Press, pp. 241-58.

Bradshaw, J., Levitas, R. and Finch, N. (2000) 'Lone parents, poverty and social exclusion', PSE Working Paper no. 11, Bristol: University of Bristol, Centre for Research in Social Policy.

Burchardt, T., Le Grand, J. and Pichaud, D. (1999) 'Social exclusion in Britain 1991-1995', Social Policy and Administration, 33, 3, 27-44.

Cattan, M., White, M., Bond, J. and Learmouth, A. (2005) 'Preventing social isolation and loneliness among older people: a systematic review of health promotion interventions', Aging and Society, 25, $1,41-67$.

Cherry, R. (2007) 'Gender and aging', in A. Borowski, S. Encel and E. Ozanne (eds.), Longevity and Social Change in Australia, Sydney: University of New South Wales Press, pp. 99-116.

Coleman, J. S. (1990) Foundations of Social Theory, Cambridge, MA: Harvard University Press.

Collery, H. (2002) 'Engagement mentoring for "disaffected" youth: a new model of mentoring for social inclusion', British Educational Research Journal, 29, 4, 521-42.

Connell, R. (2009) Gender: In World Perspective, Cambridge: Polity Press.

Craig, L. and Mullan, K. (2009) 'The policeman and the part-time sales assistant: household labour supply, family time and subjective time pressure in Australia, 1997-2006', Journal of Comparative Family Studies, 40, 4, 545-60.

De Vaus, D., Gray, M., Qu, L. and Stanton, D. (2009) 'The effect of relationship breakdown on income and social exclusion', Paper presented to the Australian Social Policy Conference, University of New South Wales, Sydney, 8 July.

Department of Social Security (1999) Opportunity for All: Tackling Poverty and Social Exclusion, First Annual Report, Cm 4445, London: Department of Social Security.

Dunn, K., Forrest, J., Burnley, I. and Mcdonald, A. (2004) 'Constructing racism in Australia', Australian Journal of Social Issues, 39, 4, 409-30.

England, P. (2005) 'Gender inequality in labour markets: the role of motherhood and segregation', State and Society, 12, 2, 264-88.

Findlay, R. and Cartwright, C. (2002) Social Isolation and Older People: A Literature Review, Brisbane: Australasian Centre on Ageing, University of Queensland.

Fleming, A. A. (1999) 'Older men in contemporary discourses on ageing: absent bodies and invisible lives', Nursing Inquiry, 6, 1, 3-8.

Flood, M. (2005) Mapping Loneliness in Australia, Discussion Paper 76, Canberra: The Australia Institute.

Fozdar, F. (2011) 'Social cohesion and skilled Muslim refugees in Australia: Employment', Journal of Sociology, 48, 2, 167-86.

Franklin, A. and Tranter, B. (2008) Loneliness in Australia, Housing and Community Research Unit Paper 13, Hobart: University of Tasmania, pp. 1-26.

Gerstel, N., Riessman, C. K. and Rosenfield, S. (1985) 'Explaining the symptomatology of separated and divorced women and men: the role of material conditions and social networks', Social Forces, 64, 1, 84-101. 
Gordon, D. (2006) 'The concept and measurement of poverty', in C. Pantazis, D. Gordon and R. Levitas (eds.), Poverty and Social Exclusion in Britain: The Millennium Survey, Bristol: The Policy Press, pp. 29-69.

Gornick, J. and Janti, M. (2010) 'Women, poverty and social policy regimes: a cross-national analysis', in P. Saunders and R. Sainsbury (eds.), Social Security, Poverty and Social Exclusion in Rich and Poorer Countries, Antwerp: Intersentia.

Grahame, T. and Marston, G. (2011) 'Welfare-to-work and the experience of single mothers in Australia: where are the benefits?', Australian Social Work, 65, 1, 73-86.

Gray, A. (2009) 'The social capital of older people', Ageing and Society, 29, 1, 5-31.

Hawthorne, G. (2008) 'Perceived social isolation in a community sample: its prevalence and correlates with aspects of peoples' lives', Social Psychiatry and Psychiatric Epidemiology, 43, 2, 140-50.

Hayes, A., Gray, M. and Edwards, B. (2008) Social Inclusion: Origins, Concepts and Key Themes, report prepared by Australian Institute of Family Studies for Social Inclusion Unit, Canberra: Department of the Prime Minister and Cabinet.

Heady, B. and Warren, D. (2007) Families Income and Jobs, Volume 2: A Statistical Report on Waves 1 to 4 of the HILDA Survey, Melbourne: Institute of Applied Economic and Social Research, University of Melbourne.

Hills, J., Le Grand, J. and Pichaud, D. (2002) Understanding Social Exclusion, Oxford: Oxford University Press.

Hughes, P. and Black, A. (2002) 'The impact of various personal and social characteristics on volunteering', Australian Journal of Volunteering, 7, 2, 59-69.

Hulse, K., Jacobs, K., Arthurson, K. and Spinney, A. (2011) At Home and in Place? The Role of Housing in Social Inclusion, AHURI Final Report no. 177, Melbourne: Australian Housing and Urban Research Institute.

Hulse, K. and Saugeres, L. (2008) Home Life, Work and Housing Decisions: A Qualitative Analysis, National Research Venture 1 Research Paper 7, February, Melbourne: Australian Housing and Urban Research Institute.

Jackson, C. (1999) 'Social exclusion and gender', The European Journal of Development Research, 11, 1, 125-46.

Joiner, T. E., Lewinsohn, P. M. and Seeley, J. R. (2002) 'The core of loneliness: lack of pleasurable engagement - more so than painful disconnection - predicts social impairment, depression onset and recovery from depressive disorders among adolescents', Journal of Personality Assessment, 79, 3, 472-91.

Kawachi, I. and Berkman, L. F. (2001) 'Social ties and mental health', Journal of Urban Health, 78, 3, 458-67.

Levitas, R., Pantazis, C., Fahmy, E., Gordon, D., Lloyd, E. and Patsios, D. (2007) The Multi-Dimensional Analysis of Social Exclusion, Bristol: Department of Sociology and School for Public Policy, University of Bristol.

Lindsay, C. (2009) 'In a lonely place? Social networks, job seeking and the experience of long-term unemployment', Social Policy and Society, 9, 1, 25-37.

Lowenthal, M. F. and Haven, C. (1968) 'Interaction and adaptation: intimacy as a critical variable', American Sociological Review, 3, 3, 20-30.

Mack, J. and Lansley, S. (1985) Poor Britain, London: George Allen \& Unwin.

Millar, J. (2003) 'Gender, poverty and social exclusion', Social Policy and Society, 2, 3, 181-8.

Millar, J. (2007) 'Social exclusion and social policy research: defining exclusion', in D. Abrams, J. Christian and D. Gordon (eds.), Multidisciplinary Handbook of Social Exclusion Research, Chichester: Wiley.

Miller, E., Buys, L. and Barnett, K. (2005) 'Feeling blue? The importance of a confidant for the wellbeing of older rural married Australian and American men', paper presented the 38th Australian Association of Gerontology Conference, Surfers Paradise, QLD.

Ogg, J. (2005) 'Social exclusion and insecurity among older Europeans: the influence of welfare regimes', Ageing and Society, 25, 1, 69-90. 
Osborne, K., Baum, F. and Ziersch, A. (2008) 'Negative consequences of community group participation for women's mental health and wellbeing: implications for gender aware social capital building', Journal of Community and Applied Social Psychology, 19, 3, 212-24.

Parks-Yancy, R., Di Tomaso, N. and Post, C. (2006) 'The social capital resources of gender and class groups', Sociological Spectrum, 26, 1, 85-113.

'Patulny, R. (2009) 'The golden years? Social contact amongst retired men and women in Australia', Family Matters, 83, 39-47.

Patulny, R. and Svendsen, G. (2007) 'The social capital grid: bonding, bridging, qualitative, quantitative', International Journal of Sociology and Social Policy, 27, 1, 32-51.

Pinquart, M. and Sörensen, S. (2001) 'Gender differences in self-concept and psychological well-being in old age: a meta-analysis', Journal of Gerontology, 56B, 4, 195-213.

Putnam, R. D. (2000) Bowling Alone: The Collapse and Revival of American Community, New York, London: Simon \& Schuster.

Rees, T., (1998) 'Social exclusion and equal opportunities', International Planning Studies, 3, 1, 15-34.

Robinson, J. P. and Godbey, G. (1997) Time for Life: The Surprising Ways Americans Use Their Time, University Park, PA: Pennsylvania State University.

Rosenman, L. and Scott, W. (2009) 'Financing old age: why is there still gender inequality', Australian Social Work, 62, 2, 287-98.

Saunders, P. and Sutherland, K. (2006) Experiencing Poverty: The Voices of Low-Income Australians, Towards New Indicators of Disadvantage Project Stage I: Focus Group Outcomes, Sydney: Social Policy Research Centre, University of New South Wales.

Saunders, P., Naidoo, Y. and Griffiths, M., (2007) Towards New Indicators of Disadvantage: Deprivation and Social Exclusion in Australia, SPRC Report, November 2007, Sydney: Social Policy Research Centre, University of New South Wales.

Scott, G. (2008) 'Gender, poverty and wealth', in T. Ridge and S. Wright (eds.), Understanding Inequality, Poverty and Wealth: Policies and Prospects, Bristol: The Policy Press, pp. 135-54.

Shapiro, A. and Keyes, C. L. M. (2008) 'Marital status and social well-being: are the married always better off?', Social Indicators Research, 88, 2, 329-46.

Stone, W., Grey, M. and Hughes, J. (2003) Social Capital at Work: How Family, Friends and Civic Ties Relate to Labour Market Outcomes, Australian Institute of Family Studies, Research Paper Number 31, Melbourne: Australian Institute of Family Studies.

Timberlake, S. (2005) 'Social capital and gender in the workplace', Journal of Management Development, $24,1,34-44$.

Torezani, S., Colic-Peisker, V. and Fozdar, F. (2008) 'Looking for a "missing link": formal employment services and social networks in refugees' job search', Journal of Intercultural Studies, 29, 2, 135-52.

van Emmerick, I. J. H. (2006) 'Gender differences in the creation of different types of social capital: A multilevel study', Social Networks, 28, 1, 24-37.

Warburton, J. and Cordingley, S. (2004) 'The contemporary challenges of volunteering in an ageing Australia', Australian Journal on Volunteering, 9, 2, 67-74.

Yuval-Davis, N. (2006) 'Intersectonality and feminist politics', European Journal of Women's Studies, 13, 3, 193-209. 
Reproduced with permission of the copyright owner. Further reproduction prohibited without permission. 